\title{
MCM-41-based composite with enhanced stability for Cr(VI) removal from aqueous media
}

\author{
Pedro Martin ${ }^{\text {a }}$, Matías Rafti ${ }^{\mathrm{b}}$, Sergio Marchetti ${ }^{\mathrm{c}}$, Nicolas Fellenz ${ }^{\mathrm{a}, *}$

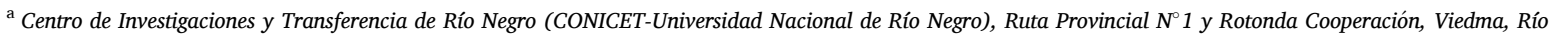 \\ Negro, Argentina \\ ${ }^{\mathrm{b}}$ Instituto de Investigaciones Fisicoquímicas Teóricas y Aplicadas (CONICET- Universidad Nacional de La Plata), Diagonal 113 y Calle 64, La Plata, Buenos Aires, \\ Argentina \\ ${ }^{c}$ Centro de Investigación y Desarrollo en Ciencias Aplicadas Dr. Jorge Juan Ronco (CONICET- Universidad Nacional de La Plata), Calle $47 \mathrm{~N} 257$, La Plata, Buenos \\ Aires, Argentina
}

\section{A R T I C L E I N F O}

\section{Keywords:}

Aminopropyl-MCM-41

Aminopropyl-methyl-MCM-41

Chromium

Stability

Sorbents

\begin{abstract}
A B S T R A C T
Two mesoporous ordered silica with MCM-41 pores arrangement were synthesized and surface modified by a post-synthetic treatment. The first composite has aminopropyl functionalities while the other features aminopropyl and methyl surface groups. Both composites were used as sorbents for $\mathrm{Cr}$ (VI) removal from aqueous media at $\mathrm{pH}=2$. In order to test the stability and durability of the sorbents, the samples were subjected to alkaline extreme conditions $(\mathrm{pH}=10)$ at different times and after that tested again for $\mathrm{Cr}(\mathrm{VI})$ removal. The bifunctionalized MCM-41 retains its $\mathrm{Cr}(\mathrm{VI})$ elimination capacity unchanged after $16 \mathrm{~h}$ of alkaline treatment, while the aminopropyl-MCM-41 sample suffer a drop of about $30 \%$. The fresh and alkaline treated samples were characterized by $\mathrm{X}$ ray diffraction at low angles, nitrogen sorption at $77 \mathrm{~K}$, Fourier transform infrared, Thermal analysis. The presence of the methyl moieties increases the hydrophobicity of the composite's surface, which inhibit the approaching of the water molecules avoiding the hydrolysis of Si-O-Si bonds of the MCM-41 pores walls. Besides, this protective effect is reflected in the textural properties changes before and after alkaline treatments: while the specific surface area of aminopropyl-MCM-41 goes from an initial value of 793 to $495 \mathrm{~m}^{2}$ $\mathrm{g}^{-1}(-37.6 \%)$, the aminopropyl-methyl-MCM-41 shows a change from 702 to $650 \mathrm{~m}^{2} \mathrm{~g}^{-1}(-7.2 \%)$. From these results it can be concluded that a second functionalizing agent that expose methyl-residues increases the stability of an aminopropyl-MCM-41 based-material, increasing the potential of this type of nanostructured composites for aqueous media applications.
\end{abstract}

\section{Introduction}

The family of nanostructured mesoporous materials known as M41S feature interesting characteristics including regular arrays of cylindrical pores, high specific surface area, controllable pore diameters ranging between 2 and $10 \mathrm{~nm}$, good thermal stability, a highly tailorable surface chemistry and low cost of manufacture, which make it appealing for its application in different adsorption-based technologies [1,2]. The ability to control surface composition through the anchorage of different chemical species and the unique structural properties of such porous materials, give rise to a large quantities of different kind of composites with several types of actives sites [3,4]. As an example, amino-modified MCM-41, a member of this family with hexagonal mesoporous arrangement, has proved to be a good candidate for environmental [5], biotechnological [6] and pharmaceutical [7] applications. This organic-inorganic composite has the ability of generating electrostatic interaction with diverse analytes, showing good performance and selectivity in these adsorption-based processes even when analytes are immersed in complex aqueous matrices [8,9]. This mesoporous silica-based framework has a surface charge which is modulated by $\mathrm{pH}$ due to the presence of $-\mathrm{NH}_{2}$ and $\mathrm{Si}-\mathrm{OH}$ surface groups, which have $\mathrm{pKa}$ values of $\approx 9$ and $\approx 7$, respectively [10].

Remediation of contaminated water sources is a priority concern worldwide where the application of silica-based composites as sorbents can offer practical and efficient solutions. This is mainly because the remediation of contaminated water through adsorption phenomenon is a simple process, which can even be carried out in undeveloped or rural areas without electricity. However, due to the wide range of possible

\footnotetext{
* Corresponding author.

E-mail address: nfellenz@unrn.edu.ar (N. Fellenz).
} 
adsorption targets environmentally hazardous, it is usually necessary to explore extended ranges of separation parameters (e.g., temperature, $\mathrm{pH}$, contact times) in order to identify the optimal conditions for the studied process [11]. Considering hexavalent chromium anions as an example, its removal from water using amine-functionalized MCM-41 occurs optimally at acidic conditions, i.e. $\mathrm{pH} \leq 3$, and temperatures between 20 and $40{ }^{\circ} \mathrm{C}$ [12]. For example, Bao and coworkers synthesized porous $\mathrm{NH}_{2}$-MCM-41 nanoparticles with uniform hydrophilic and adsorptive surface which shows good adsorption capacity for $\mathrm{Cr}$ (VI) reaching equilibrium around $5 \mathrm{~min}$ [13]. Lai et al. synthesized three types of amino-functionalized mesoporous nanospheres using an indirect co-condensation method and applied this nanocomposites for $\mathrm{Cr}(\mathrm{VI})$ removal at experiments conducted under room temperature using Cr-contained solution $(100 \mathrm{~mL}, 20 \mathrm{mg} \mathrm{L}-1)$ under $\mathrm{pH} \mathrm{3}$, finding a maximum adsorption capacity of $279.92 \mathrm{mg} \mathrm{g}^{-1}$ for the N-(3-trimethoxysilylpropyl)diethylenetriamine functionalized composite [14].

At the temperatures and low $\mathrm{pH}$ values mentioned above as optimal operational conditions, chromium mainly is as $\mathrm{Cr}_{2} \mathrm{O}_{7}^{2-}(\approx 35 \%)$ and $\mathrm{HCrO}_{4}^{-}(\approx 65 \%)$, while the solid's surface remain positively charged [15, 16]. This situation promotes the sorbate-adsorbent interaction, and, in the case of amino-containing sorbents, the existence of amino moieties also generates the chemical transformation of $\mathrm{Cr}$ (VI) to the less toxic $\mathrm{Cr}$ (III) species [17]. Conversely, in order to desorb and recover the metal for sorbent re-use, it is necessary first to treat the spent sorbent (metal-loaded sorbent) in alkaline conditions [11,18]. An opposite situation occurs when cations are the target to remove (e.g. $\mathrm{Cu}(\mathrm{II}), \mathrm{Cr}(\mathrm{III}), \mathrm{Fe}(\mathrm{II})$, $\mathrm{Hg}(\mathrm{II})$ ). In these cases the adsorption step occurs at neutral or basic conditions, because these metals likely exist, in the investigated $\mathrm{pH}$ ranges, with positive net charge while the solid surface is negatively charged [19]. In the cation removal cases the desorption-regeneration step must carried out at acidic conditions [20].

Silica-based mesoporous materials suffer pore wall dissolution and pore collapse by hydrolysis of $\mathrm{Si}-\mathrm{O}$ bonds when they are exposed to neutral or alkaline $\mathrm{pH}$ conditions, losing their main structural features [21]. The dissolution mechanism of solid ordered mesoporous silica structures, such as in the MCM-41, in aqueous environments is relatively well understood and it was reported extensively in the past. It can be summarized as follows: the stability of particles of these solids in water is strongly $\mathrm{pH}$ dependent and decreases dramatically under alkaline conditions due to the increasingly higher deprotonation of silanol surface groups and hydrolysis of $\mathrm{Si}-\mathrm{O}-\mathrm{Si}$ bonds [22]. A pioneer work that searched how to evaluate and improve the stability of MCM-41 samples was reported by Kisler et al. These authors described the incorporation of a hydrophobic coating over MCM-41 surface demonstrating that such modification causes that the material retains its regular structure and uniform pore size after over 12 days exposure to aqueous environments at $\mathrm{pH} \cong 6$ [23]. Other path to reinforce silica skeleton and therefore, the durability of MCM-41-based systems is to increase the wall thickness by applying different synthesis procedures [24]. An increasing of temperature during the sol-gel step in the synthesis mixture, resulted in the enlargement of pore size and some reduction of long-range ordering but at the same time thicker pore walls are generated [25]. The addition of salts in the gel synthesis mixture give rise to an improvement of hydrothermal stability of the final mesoporous silica structure [26]. On the other hand, a post-synthetic aging procedure at $\mathrm{pH}=7.5$ was found to be one the most efficient way to reinforce the silica framework since this treatment increases thermal and hydrothermal stability of a silica-based solid [27]. However, the study and improvement of the stability of functionalized MCM-41 for its use in aqueous environments under extreme $\mathrm{pH}$ conditions, i.e. alkaline conditions, have received less attention. Although such improvement would contribute to overcome two critical effects which lead to lower adsorption performances: partial dissolution of the silica network, and loss of the surface grafted moieties (leaching). These functionalizing groups endow the surface with the desired adsorption properties. Therefore, for the application of ordered mesoporous silica in real and concrete processes, the above mentioned issues must be addressed, with the aim that the performance remains relatively constant after repeated adsorption-regeneration cycles. This is an essential objective if intend to have a long-life adsorbent.

Taking into account these considerations, the aim of the present work is to evaluate the stability of an aminopropyl-modified MCM-41 composite with its hydrophobicity increased by a second functionalizing agent that expose methyl-residues. Both, mono (aminopropyl) and bifunctionalized (aminopropyl-methyl) MCM-41 structures were synthesized through covalently bonded amino and amino/methyl moieties on the pore walls. These materials were exposed to extremely alkaline $\mathrm{pH}$ conditions $(\mathrm{pH}=10)$. Before and after this alkaline treatment, $\mathrm{Cr}(\mathrm{VI})$ adsorption performance was evaluated in aqueous solutions at room temperature and $\mathrm{pH}=2$. Hexavalent chromium was chosen as a model analyte because this metal is at the top-priority list of toxic inorganic pollutants defined by the US Environmental Protection Agency due to its mutagenic and carcinogenic properties against biological species [28, 29].

\section{Experimental}

\subsection{Reactants}

Analytical grade reagents were used as received from Sigma-Aldrich. Hexadecyltrimethyl-amonnium bromide (CTAB, $\geq 98 \%$ ) was used as structure directing agent, tetraethyl orthosilicate (TEOS, $\geq 99 \%$ ) was used as silica source, and surface modification was carried using aminopropyl-triethoxysilane (APTES, $\geq 98 \%$ ), methyltrimethoxy silane (MTMS, 98\%). Besides, toluene, absolute ethanol, potassium dichromate, hydrochloric acid, sulfuric acid and ammonium hydroxide were other reagents used.

\subsection{Synthesis and functionalization of MCM-41}

As-synthesized MCM-41 starting material was obtained following the sol-gel procedure of Grün et al., which is a variation of the Stöber synthesis used for preparation of monodispersed silica spheres [30]. For this work and in order to obtain $\approx 1.0 \mathrm{~g}$ of pure MCM- $41,40 \mathrm{~mL}$ of distilled water, $24 \mathrm{~mL}$ of $\mathrm{NH}_{4} \mathrm{OH}, 2 \mathrm{~g}$ of CTAB, $60 \mathrm{~mL}$ of absolute ethanol and 4 $\mathrm{mL}$ of TEOS were mixed using vigorous magnetic stirring at $30^{\circ} \mathrm{C}$ for $2 \mathrm{~h}$. After such reaction time, a white precipitate was collected by filtration and washed exhaustively with distilled water. To remove the template agent the sample was calcined at $550^{\circ} \mathrm{C}$ in air atmosphere for $2 \mathrm{~h}$, with a heating rate of $5{ }^{\circ} \mathrm{C} \mathrm{min}^{-1}$. The final sample obtained was labelled MCM-41. The two organic-inorganic samples were obtained by post-synthetic functionalization procedures carried over the starting MCM-41 obtained as detailed below. The aminopropyl-modified MCM-41 was produced by mixing $0.5 \mathrm{~g}$ of MCM-41 with APTES $(0.5$ $\mathrm{mL})$ in toluene $(50 \mathrm{~mL})$ at $80{ }^{\circ} \mathrm{C}$ under vigorous stirring. After $6 \mathrm{~h}$ of treatment the final product, called MCM- $41-\mathrm{NH}_{2}$, was separated by filtration and repeatedly washed with ethanol and water in order to remove the unreacted physisorbed APTES. In the case of the aminopropyl/methyl-modified MCM-41 sample, the same procedure just described was carried out, but the $50 \mathrm{~mL}$ toluene solution was composed by $0.5 \mathrm{~mL}$ of APTES plus $2.5 \mathrm{~mL}$ of MTMS. The modified material will be referred from hereafter as $\mathrm{MCM}-41-\mathrm{NH}_{2}-\mathrm{CH}_{3}$.

\subsection{Alkaline treatments. Stability assays}

As it was already mentioned there is a growing interest in the synthesis of robust and long-lived adsorbents, which can be used (and reused) in aqueous environments with different chemical properties and compositions. In order to attend this requirement, the freshly synthesized samples, as described in section 2.2, were subjected to alkaline treatments in a $\mathrm{NaOH}$ aqueous solution ( $\mathrm{pH} 10)$ during 8 and $16 \mathrm{~h}$. In this way, two new sets of samples, were obtained. These samples were labelled as MCM-41-NH $2-8, \mathrm{MCM}-41-\mathrm{NH}_{2}-16, \mathrm{MCM}-41-\mathrm{NH}_{2}-\mathrm{CH}_{3}-8$ and 
MCM-41- $\mathrm{NH}_{2}-\mathrm{CH}_{3}-16$, where 8 and 16 indicate the duration in hours of alkaline treatment.

\subsection{Adsorption experiments}

With the objective of evaluating the possible structural damage and leaching of functional groups in the modified MCM-41 samples due to alkaline treatment (which simulates regeneration cycles carried out on the sorbents), and the impact of such treatment in the chromium adsorption performance in acidic conditions, adsorption experiments were carried using both fresh and alkaline treated samples. At this stage it is important to remark that the chromium elimination capacity of an amine-MCM-41-based sorbent reaches its maximum value in the $\mathrm{pH}$ range between 2 and 3 [31], but the regeneration of the spent sorbent for a next use implies an alkaline treatment in order to produce chromium desorption. Thus, adsorption experiments were performed with the six samples as follows: $15 \mathrm{~mL}$ of $\mathrm{K}_{2} \mathrm{Cr}_{2} \mathrm{O}_{7}$ aqueous solution of different concentrations between 10 and $130 \mathrm{ppm}$ and $\mathrm{pH}$ adjusted to the optimal value of $2 \pm 0.2$ using $\mathrm{HCl}$, were mechanically stirred with $15 \mathrm{mg}$ of the desired sorbent at $25{ }^{\circ} \mathrm{C}$ for $24 \mathrm{~h}$. The adsorption optimal conditions (temperature, time and $\mathrm{pH}$ ) were selected according previously reported data [18]. After the contact time was elapsed, solids were separated by centrifugation (9000 rpm, $5 \mathrm{~min}$ ). Cr (VI) concentration in the supernatant was measured by visible-UV spectroscopy following adsorption bands centered at $540 \mathrm{~nm}$ wavelength, and the total chromium concentration was measured in each case by inductively coupled plasma-optical emission spectroscopy (ICP-OES) using an Agilent 4100 MP-AES nitrogen microwave plasma atomic emission spectrometer controlled by using Agilent MP Expert Software. The amount of trivalent chromium, that could have been generated, was calculated by difference between these two quantification methods. All the adsorption experimental data were adjusted using the Langmuir isotherm model, and thus the maximum adsorption capacity, $\mathrm{q}_{\max }$, was calculated using equation (1):

$\mathrm{C}_{\mathrm{e}} / \mathrm{q}_{\mathrm{e}}=1 / \mathrm{K}_{\mathrm{L}} \mathrm{q}_{\max }+\mathrm{C}_{\mathrm{e}} / \mathrm{q}_{\max }$

where $C_{e}$ is the concentration of adsorbate in equilibrium in the supernatant expressed in mg. $\mathrm{l}^{-1}, \mathrm{q}_{\mathrm{e}}$ is the adsorbed amount in equilibrium conditions expressed in mg. ${ }^{-1}, \mathrm{~K}_{\mathrm{L}}\left(\mathrm{L} \cdot \mathrm{mg}^{-1}\right)$ is the Langmuir constant which is related to the intensity adsorbent/adsorbate interaction and $\mathrm{q}_{\max }$ is the maximum adsorption capacity of the adsorbent expressed in mg of adsorbate per $\mathrm{g}$ of adsorbent.

\subsection{Characterization of fresh and alkaline treated MCM-41 samples}

The mesoporous ordered silica structure of the samples synthesized was analyzed by X-ray diffraction (XRD) using a standard automated powder X-ray diffraction equipment (Philips PW 1710) provided with diffracted-beam graphite monochromator and $\mathrm{Cu} \mathrm{K} \alpha$ radiation in the $2 \theta$ range between $1.5^{\circ}-7^{\circ}$ with steps of $0.02^{\circ}$ and acquisition time of $2 \mathrm{~s}$. $\mathrm{step}^{-1}$. Fourier transformed infrared spectra (FT-IR) of dried samples mixed with $\mathrm{KBr}$ (ratio $\approx 1: 100$ ), were obtained on a Nicolet iS5 Thermo scientific spectrometer equipped with a Pike Diffuse IR cell with a resolution of $1 \mathrm{~cm}^{-1}$. The textural properties: specific surface area (Sg), pore volume $(\mathrm{Vp})$ and average pore diameter $\left(\mathrm{D}_{\mathrm{p}}\right)$ were obtained from the nitrogen adsorption-desorption isotherms recorded at $-196{ }^{\circ} \mathrm{C}$ on samples dried overnight at $100{ }^{\circ} \mathrm{C}$ under vacuum in a Micromeritics equipment ASAP 2020 V1.02 E. The pore size distribution was determined using the Barret-Joyner-Halenda/Kruk-Jaroniec-Sashari method (BJH-KJS). Thermal analysis (TGA) were performed on a TAInstruments Q-Series apparatus, upon heating the samples from room temperature to $750{ }^{\circ} \mathrm{C}$ at a heating rate of $5^{\circ} \mathrm{C} \mathrm{min}-1$ under air flow $(20$ $\mathrm{mL} \min ^{-1}$ ).

\section{Results and discussion}

\subsection{Characterization of the samples}

\subsubsection{Characterization of fresh samples}

The solid structures on the as-prepared MCM-41 and fresh functionalized samples were studied by XRD at low angles. The X-ray diffraction patterns of MCM-41, MCM-41-NH $\mathrm{NH}_{2}$ and MCM-41- $\mathrm{NH}_{2}-\mathrm{CH}_{3}$ are depicted in Fig. 1 . In all cases an intense main peak at $2 \theta=2.5^{\circ}$ and two wide and less intense peaks in the $4-6^{\circ} 2 \theta$ region can be observed. These peaks are associated with the highly $2 \mathrm{D}$ hexagonal p6m mesopores arrangement typical of MCM-41 mesophase (JCPDS data base number 00-049-1712) [32]. In the non-modified MCM-41 these three signals are more pronounced than in the functionalized samples. These changes can be associated with the filling of the mesopores with organic moieties, which induces a decrease in the electron density difference between pores and silica walls, producing a decrease in the intensity of the XRD signals [33]. Therefore, it can be concluded that post-synthesis functionalization with APTES (in the case of MCM-41- $\mathrm{NH}_{2}$ ) and with APTES/MTMS mixture (for MCM-41- $\mathrm{NH}_{2}-\mathrm{CH}_{3}$ ), does not generate significant structural changes.

FT-IR spectra of non-modified and functionalized MCM-41 are presented in Fig. 2. The bands corresponding to characteristic Si-O-Si vibrational modes of inorganic framework can be observed at $800 \mathrm{~cm}^{-1}$ and in the $950-1300 \mathrm{~cm}^{-1}$ range for all samples [34]. Clear differences between the spectrum of the starting MCM-41 and the functionalized materials are visualized. Amino functions give rise in the functionalized samples to a broad band in the $3000-3600 \mathrm{~cm}^{-1}$ region $(\nu \mathrm{NH})$, which superimpose to the large $\mathrm{O}-\mathrm{H}$ stretching bands of adsorbed water and surface hydroxyl groups. Similarly, bending $\mathrm{O}-\mathrm{H}$ vibrational modes corresponding to adsorbed water appear centered at $1650 \mathrm{~cm}^{-1}$, with higher intensity for as prepared MCM-41 material than for functionalized MCM-41 [35]. These results would indicate a greater amount of surface-confined adsorbed water in the pure MCM-41 sample. Additional vibrational bands observed at 2940 and $2970 \mathrm{~cm}^{-1}$, can be associated to $\mathrm{C}-\mathrm{H}$ stretching modes from the organic attached functionalities chains, in MCM-41- $\mathrm{NH}_{2}$ and MCM-41- $\mathrm{NH}_{2}-\mathrm{CH}_{3}$ materials [36]. Aminopropyl moieties grafted on the pore walls of both modified MCM-41 samples can be inferred from the presence of a band at 1550 $\mathrm{cm}^{-1}$ assignable to $\mathrm{N}-\mathrm{H}$ bending vibration modes [37]. An additional small band at $1275 \mathrm{~cm}^{-1}$ appears in the spectrum of MCM-41- $\mathrm{NH}_{2}-\mathrm{CH}_{3}$ which can be associated to $\mathrm{Si}-\mathrm{CH}_{3}$ moieties present [38]. Finally, the $960 \mathrm{~cm}^{-1}$ band, due to the $-\mathrm{OH}$ stretching mode of residual unmodified $\mathrm{Si}-\mathrm{OH}$ surface groups, decreased significantly for the modified samples

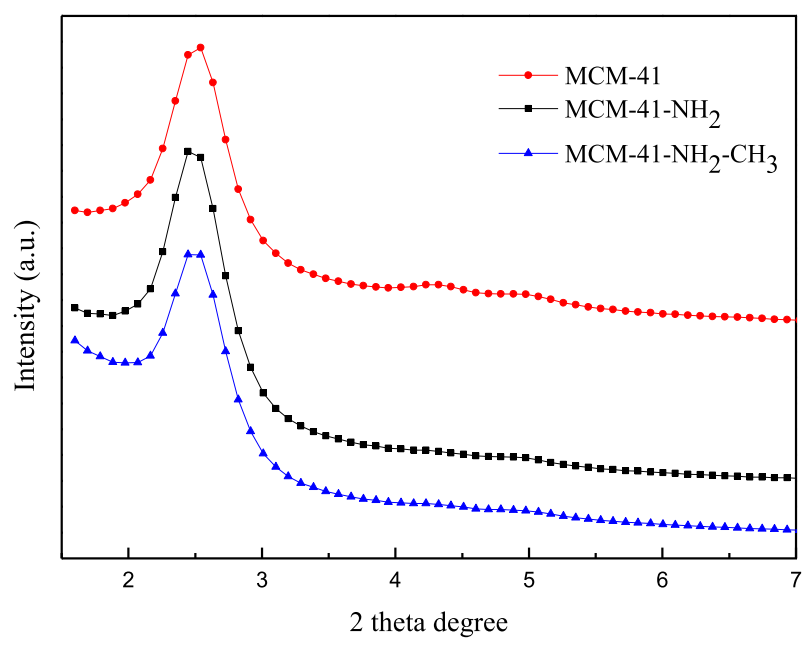

Fig. 1. XRD patterns at low angles of MCM-41 (circles), MCM-41-NH $\mathrm{H}_{2}$ (squares) and MCM-41- $\mathrm{NH}_{2}-\mathrm{CH}_{3}$ (triangles). The three diffractograms are ascribed to a MCM-41 hexagonal pore arrangement. 


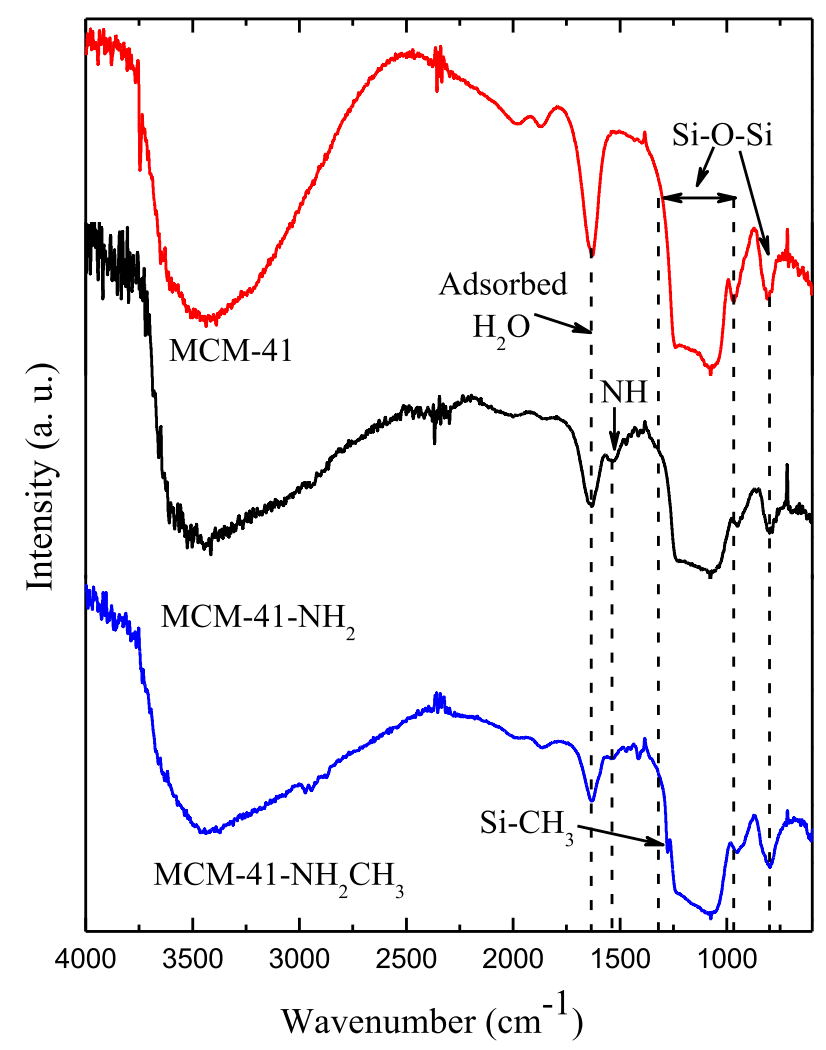

Fig. 2. Fourier transform-infrared (FT-IR) spectra of MCM-41, MCM-41-NH and MCM-41- $\mathrm{NH}_{2}-\mathrm{CH}_{3}$.

indicating that the aminopropyl groups are covalently linked and were incorporated by substituting surface silanols.

The nitrogen sorption isotherms obtained at $-196{ }^{\circ} \mathrm{C}$ for the pure and functionalized MCM-41s are shown in Fig. 3-a. All of them are type IV according to the IUPAC classification, indicating the existence of a mesoporous structure [39]. No hysteresis loop is observed for any sample. This fact can be related with the existence of mesopores smaller than $4 \mathrm{~nm}$, giving rise to a completely reversible nitrogen adsorption-desorption process, this was verified by applying the BJH-KJS method to obtain the pore sizes distribution (Fib. 3-b and Table 1). It is well known that the simultaneous presence of water traces and unreacted silanes, such as APTES and MTMS, might cause oligomerization of the silanes giving rise to a higher concentration of organic groups at the pore entrances leading to pore blocking [40]. In this sense, it is expected that increasing the silane agent concentration during the functionalization step, a higher quantity of blocked pores would be generated. Considering that, in the synthesis of $\mathrm{MCM}-41-\mathrm{NH}_{2}-\mathrm{CH}_{3}$ was used a silane concentration 6 times higher than in the MCM-41- $\mathrm{NH}_{2}$ functionalization, can be understood the differences of BET surface areas for each material (Table 1). In this way, the initial surface area of 991 $\mathrm{m}^{2} \mathrm{~g}^{-1}$ for MCM-41 decrease $\approx 20 \%$ for MCM-41- $\mathrm{NH}_{2}$ and $\approx 30 \%$ for MCM-41- $\mathrm{NH}_{2}-\mathrm{CH}_{3}$. The average pore diameter and the pore volume show very similar changes for both modified samples with respect to the bare MCM-41. Thus, a decrease of 0.6 and $0.5 \mathrm{~nm}$ for pore diameters and of about 25 and $30 \%$ for pore volume were detected for the amino and amino-methyl MCM-41, respectively. An important change was observed in the $\mathrm{C}_{\mathrm{BET}}$ constant value (Table 1 ). This parameter can be interpreted as an indication of the adsorption enthalpy between the adsorbate $\left(\mathrm{N}_{2}\right)$ and the studied solid surface [41]. Thus, $\mathrm{C}_{\mathrm{BET}}$ values changes would indicate a variation of surface hydrophobicity character [42]. In the cases here evaluated, a decrease of about $60 \%$ for the hybrid samples in comparison with MCM-41 starting material was registered. Therefore, the presence of aminopropyl surface moieties in a)

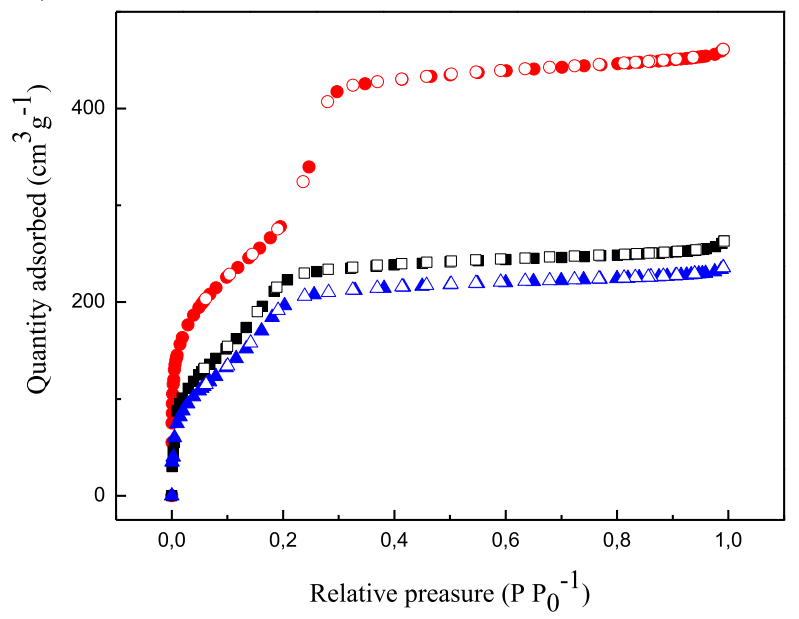

b)

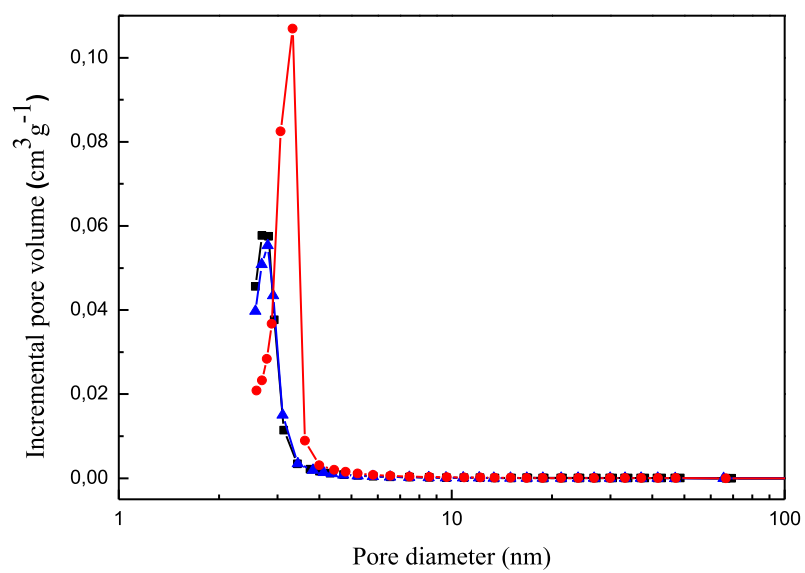

Fig. 3. a) Nitrogen adsorption (full symbols)-desorption (empty symbols) isotherms for MCM-41 (circles), MCM-41- $\mathrm{NH}_{2}$ (squares) and MCM-41- $\mathrm{NH}_{2}-\mathrm{CH}_{3}$ (triangles), b) Pore size distribution obtained by applying BJH-KJS method.

Table 1

Textural and surface properties of the MCM-41 and functionalized samples before and after alkaline treatment.

\begin{tabular}{|c|c|c|c|c|}
\hline $\begin{array}{l}\text { Sample/ } \\
\text { Parameter }\end{array}$ & $\begin{array}{l}\text { Surface area } \\
\left(\mathrm{m}^{2} \cdot \mathrm{g}^{-1}\right)^{\mathrm{a}}\end{array}$ & $\begin{array}{l}\text { Pore volume } \\
\left(\mathrm{cm}^{3} \cdot \mathrm{g}^{-1}\right)^{\mathrm{a}}\end{array}$ & $\begin{array}{l}\text { Pore diameter } \\
(\mathrm{nm})^{\mathrm{b}}\end{array}$ & $\mathrm{C}^{\mathrm{a}}$ \\
\hline MCM-41 & 991 & 0.53 & 3.3 & 101 \\
\hline MCM-41-NH & 793 & 0.40 & 2.7 & 41 \\
\hline MCM-41-NH $\mathrm{N}_{2}-8$ & 540 & 0.37 & 2.9 & 59 \\
\hline $\begin{array}{l}\text { MCM-41-NH2- } \\
16\end{array}$ & 495 & 0.44 & 2.8 & 57 \\
\hline $\begin{array}{l}\mathrm{MCM}-41-\mathrm{NH}_{2}- \\
\mathrm{CH}_{3}\end{array}$ & 702 & 0.36 & 2.8 & 39 \\
\hline $\begin{array}{l}\mathrm{MCM}-41-\mathrm{NH}_{2}- \\
\mathrm{CH}_{3}-8\end{array}$ & 750 & 0.37 & 2.9 & 45 \\
\hline $\begin{array}{l}\mathrm{MCM}-41-\mathrm{NH}_{2}- \\
\mathrm{CH}_{3}-16\end{array}$ & 650 & 0.50 & 2.8 & 51 \\
\hline
\end{tabular}

${ }^{\text {a }}$ By nitrogen sorption (BET).

b BJH-KJS method.

MCM-41- $\mathrm{NH}_{2}$ and aminopropyl-methyl organic functions in MCM-41- $\mathrm{NH}_{2}-\mathrm{CH}_{3}$, causes an increase on the hydrophobic surface character of materials. This variation is in accordance with the previously discussed FT-IR spectra, where a decrease on the intensity of vibrational bands corresponding to surface adsorbed water was detected after post-synthesis functionalization treatments.

Thermogravimetric analysis was used in order to determine the organic content from mass loss observed between 200 and $800{ }^{\circ} \mathrm{C}$ (TGA 
and 1st derivative curves are shown in Fig. 4). In Table 2 the mass losses assigned to adsorbed water and organic loading are shown. Due to the fact that around $350{ }^{\circ} \mathrm{C}$ dehydroxylation of free silanols to form siloxane bridges occurs [43], these measurements are not exact values but they can be taken as an estimation of organic loading in the functionalized samples, and they are useful for comparison purposes. The first mass loss for all samples occurred below $130{ }^{\circ} \mathrm{C}$ and is generated by water desorption [44]. The weight-percentage corresponding to physisorbed water reported in Table 2 shows a decreasing tendency for the samples in the order MCM-41/MCM-41-NH $/$ MCM-41- $\mathrm{NH}_{2}-\mathrm{CH}_{3}$. Indeed, significant weight loss is registered for the pristine sample due to water evaporation (28.5\%), while in the aminopropyl-methyl-functionalized sample falls to less than $1 \%$. An intermediate value of $3.3 \%$ was measured for the aminopropyl-functionalized one. An integrated analysis of the obtained TGA, BET and FT-IR results suggest that the incorporation of surface moieties generates an increased surface hydrophobicity with respect to pure MCM-41. MCM-41- $\mathrm{NH}_{2}$ sample shows higher organic loading than MCM- $41-\mathrm{NH}_{2}-\mathrm{CH}_{3}$. This can be understood taking into account two phenomena. At first, the higher concentration of functionalizating agents used for the synthesis of the bi-functionalized MCM-41 system, would induce a greater cross-polymerization extent between silane agent molecules inside the pores and thus a more pronounced pore blocking would occur. On the other hand, the weight difference between $-\mathrm{CH}_{3}$ and $-\left(\mathrm{CH}_{2}\right)_{3}-\mathrm{NH}_{2}$ groups would contribute to the same effect (Table 1).

a)
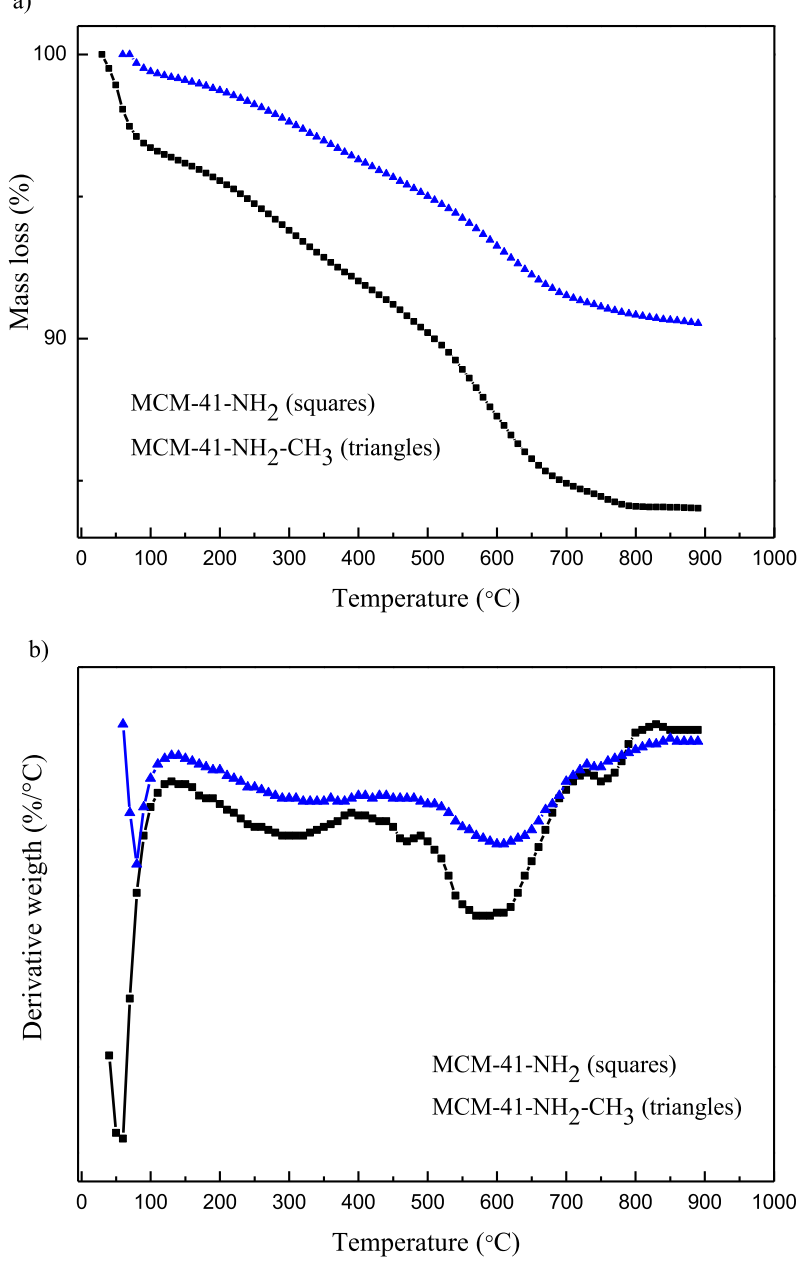

Fig. 4. a) Full TGA curves for MCM-41-NH 2 and MCM-41-NH 2 -CH 3, b) First derivative curve (DTG) obtained from TGA analysis.
Table 2

Mass losses percentages calculated from TGA analysis.

\begin{tabular}{|c|c|c|}
\hline Sample/Parameter & Water content ${ }^{\mathrm{a}}$ & Organic loading $^{\mathrm{b}}$ \\
\hline MCM-41 & 28.5 & 0 \\
\hline MCM-41-NH 2 & 3.3 & 12.7 \\
\hline MCM-41- $\mathrm{NH}_{2}-8$ & 10.2 & 10.9 \\
\hline MCM-41- $\mathrm{NH}_{2}-\mathrm{CH}_{3}$ & 0.7 & 8.8 \\
\hline MCM-41- $\mathrm{NH}_{2}-\mathrm{CH}_{3}-8$ & 4.1 & 7.5 \\
\hline
\end{tabular}

a $\%$ mass loss between 80 and $130{ }^{\circ} \mathrm{C}$.

b \% mass loss between 250 and $800{ }^{\circ} \mathrm{C}$.

\subsubsection{Characterization of alkaline treated samples}

In order to simulate regeneration procedures and/or applications of aminopropyl-MCM-41-based sorbents in processes that involves alkaline conditions, such as copper adsorption or oxyanion hexavalent chromium desorption, the aminopropyl and aminopropyl-methyl functionalized MCM-41 were immersed in $\mathrm{NaOH}$ aqueous solution $(\mathrm{pH}=10)$ during 8 and $16 \mathrm{~h}$ with magnetic stirring. After alkaline treatments, the obtained samples were characterized and compared to the initial materials, in order to analyze their stability.

Table 1 shows the textural properties values of alkaline treated samples at different times. The aminopropyl-functionalized MCM-41 shows a decreasing tendency in the surface area values obtained as the exposure time in aqueous $\mathrm{NaOH}$ increases. After $16 \mathrm{~h}$, this parameter falls $37.6 \%$, changing from an initial value of 793 to $495 \mathrm{~m}^{2} \mathrm{~g}^{-1}$. On the other hand, the increasing in $\mathrm{C}_{\mathrm{BET}}$, between 39 and $43 \%$, indicates a decrease in surface hydrophobicity because of the alkaline treatment. The textural properties changes can be associated with mesoporous structure damage (Si-O-Si hydrolysis) and aminopropyl groups leaching, since both process lead to the emergence of $\mathrm{Si}-\mathrm{OH}$ groups, decreasing in this way the surface hydrophobicity. The bi-functionalized MCM-41 presents a more complex behavior; in the beginning of the alkaline treatment (after $8 \mathrm{~h}$ ) loss of some functional groups would occur, generating an opening of the pores previously blocked in the functionalization step. Consequently, in this first stage the surface area increases from 702 to $750 \mathrm{~m}^{2} \mathrm{~g}^{-1}$. Besides, $\mathrm{C}_{\mathrm{BET}}$ changes from 39 to 45 due to the accessibility of a new set of surface silanols (initially inaccessible due to blockage of the pores) and to the loss of a percentage of the functionalizing agent. After $16 \mathrm{~h}$ in alkali, a damage to the structure can be inferred since the surface area falls to $650 \mathrm{~m}^{2} \mathrm{~g}^{-1}$, meaning a decrease of $7.2 \%$ compared to the initial value. Scheme 1 represents a behavior that would explain the changes discussed above for the bifunctionalized samples against the alkaline treatment.

In an attempt to assess the degree of loss of the organic groups due to

a)

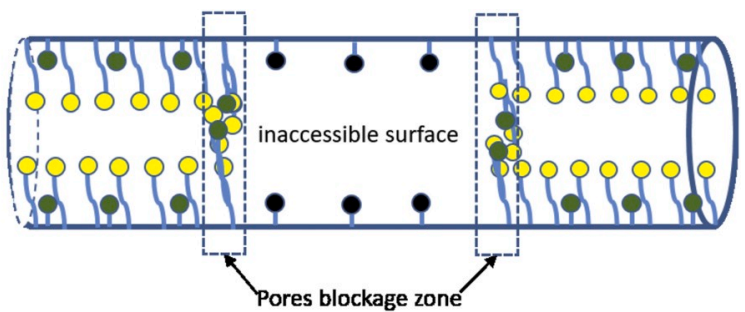

b)

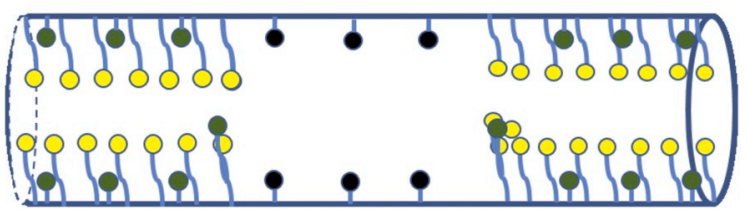

Scheme 1. Qualitative representation of the surface pore composition in the sample MCM-41-NH 2 - $\mathrm{CH} 3$, a) fresh sample before alkaline treatment, b) after alkaline treatment. Yellow circles represent amino moieties, green methyl moieties and blacks are the $\mathrm{Si}-\mathrm{OH}$ groups not modified in the functionalization step. 
the alkaline aqueous treatment, the samples MCM-41- $\mathrm{NH}_{2}-8$ y MCM-41$\mathrm{NH}_{2}-\mathrm{CH}_{3}-8$ were subjected to thermogravimetric analysis. Table 2 shows the TGA obtained data expressed as mass lost percentage. In the same way that the observed for the fresh samples, the aminopropylfunctionalized MCM-41 after $8 \mathrm{~h}$ in $\mathrm{NaOH}$ aqueous solution had a mass loss of adsorbed water greater than MCM-41- $\mathrm{NH}_{2}-\mathrm{CH}_{3}-8,10.2$ vs $4.1 \%$, respectively. This indicates the existence of a greater quantity of surface silanol moieties in the mono-functionalized MCM-41, which can interact strongly with water, in accordance with the explanation given above of the textural properties changes for this hybrid MCM-41. The weight loss associated to the oxidation of the organic functions decrease for both alkaline treated samples respect to the fresh ones, reaching values of 10.9 and $7.5 \%$ for MCM-41- $\mathrm{NH}_{2}-8$ and $\mathrm{MCM}-41-\mathrm{NH}_{2}-\mathrm{CH}_{3}-8$, respectively. The observed differences in the stability on the mono and bi-functionalized samples can be understood considering that the incorporation onto the MCM-41 surface of a hydrophobic group avoid or minimize the contact with water, water which promote the nucleophilic attack of Si-O-Si bonds giving rise to structure damage (see Fig. 5).

\subsection{Adsorption experiments}

In order to test the performance as sorbent of all samples, the fresh samples and that obtained after treatments in alkaline aqueous medium during 8 and $16 \mathrm{~h}$, were employed to remove hexavalent chromium from water. Batch adsorption experiments were performed at room temperature $\left(25 \pm 2{ }^{\circ} \mathrm{C}\right)$ and $\mathrm{pH}=2 \pm 0.2$, with mechanical stirring (500 rpm) during $24 \mathrm{~h}$ to ensure reaching equilibrium conditions. Fig. 6-a shows the maximum $\mathrm{Cr}$ (VI) elimination capacities per gram of sorbent $\left(\mathrm{q}_{\max }\right)$ calculated using the Langmuir model (Eq. (1)), while in Fig. 6-b are depicted the full adsorption isotherms for all the samples. Clearly, MCM41- $\mathrm{NH}_{2}$ shows a decreasing $\mathrm{q}_{\max }$ when the contact time with the $\mathrm{NaOH}$ solution increased. In this way, the starting value $\left(78.7 \mathrm{mg} \mathrm{g}^{-1}\right)$ decreased up to $55.6 \mathrm{mg} \mathrm{g}^{-1}(\Delta \cong 30 \%)$ after the sample was contacted with alkaline aqueous medium during $16 \mathrm{~h}$. On the contrary, the MCM- a)

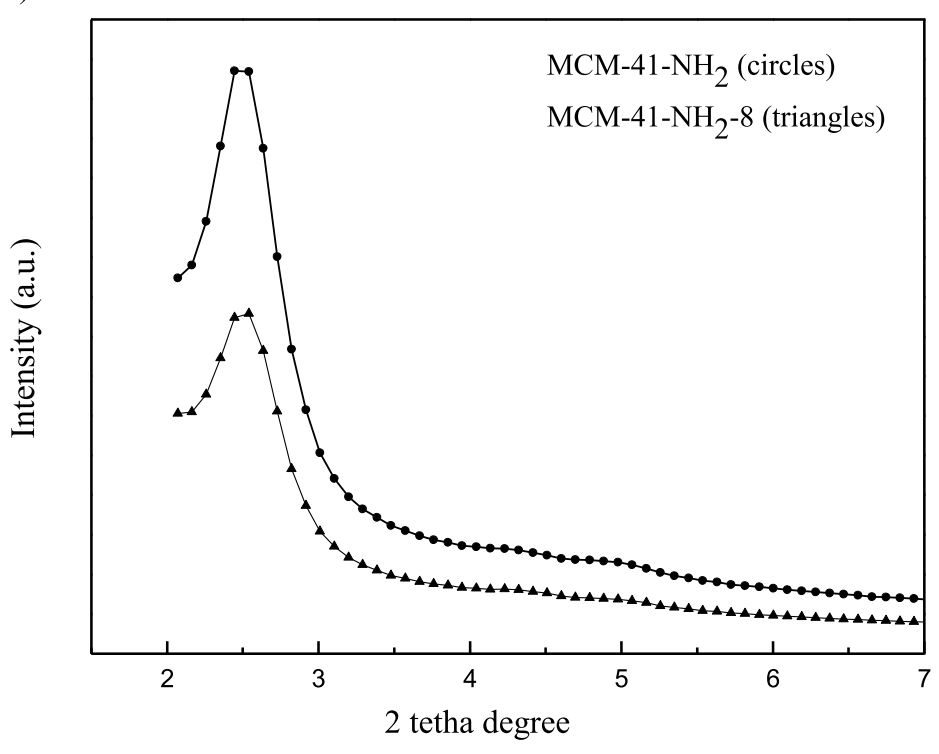

b)

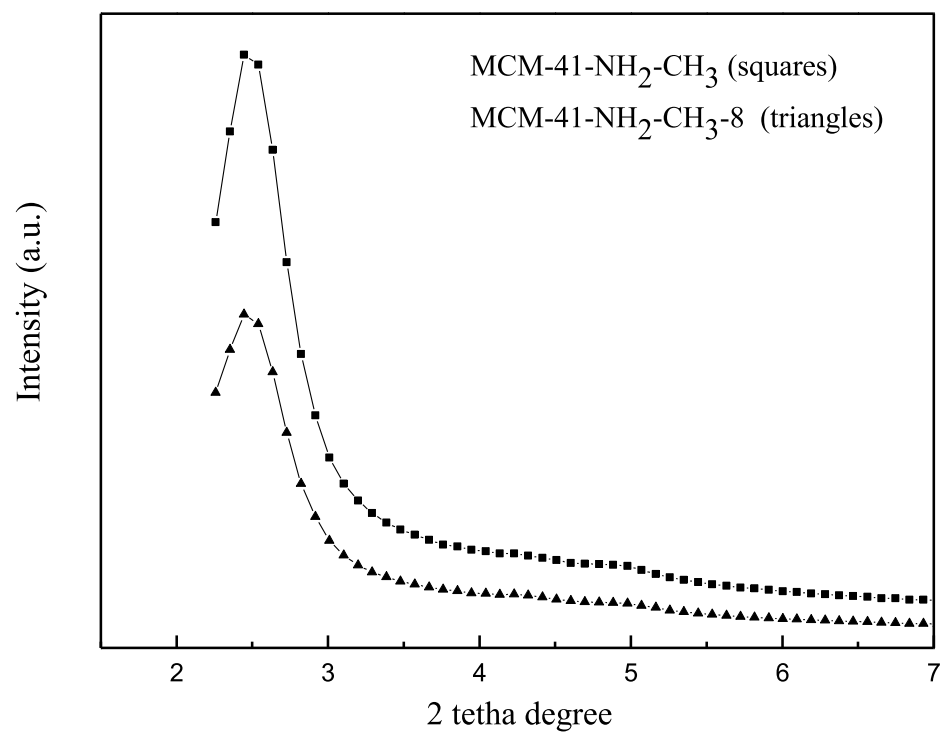

c)

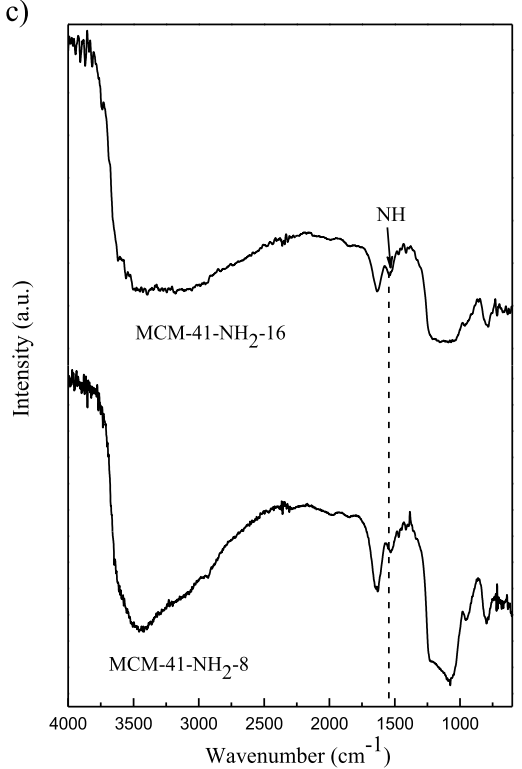

d)

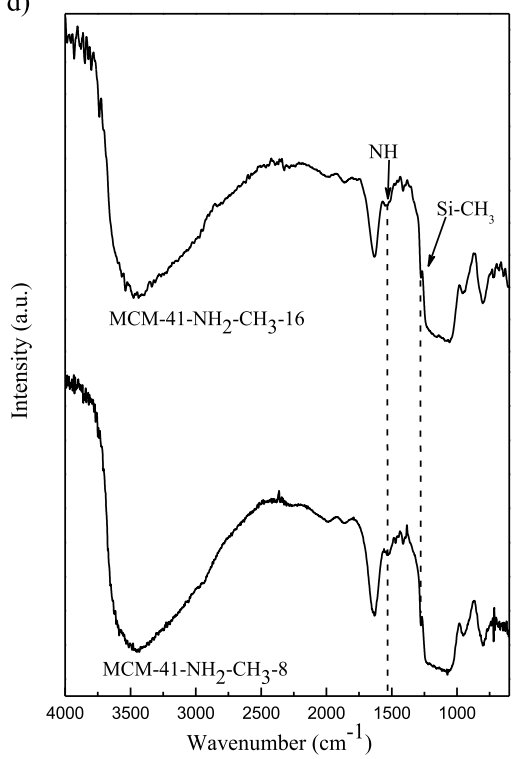

Fig. 5. XRD patterns at low angles for the alkaline treated samples, a) comparison between fresh $\mathrm{MCM}-41-\mathrm{NH}_{2}$ and $\mathrm{MCM}-41-\mathrm{NH}{ }_{2}$ treated $8 \mathrm{~h}$ at $\mathrm{pH}=10$, b) comparison between fresh MCM-41- $\mathrm{NH}_{2}-\mathrm{CH}_{3}$ and $\mathrm{MCM}-41-\mathrm{NH}_{2}-\mathrm{CH}_{3}$ treated $8 \mathrm{~h}$ at $\mathrm{pH}=10$. 
a)

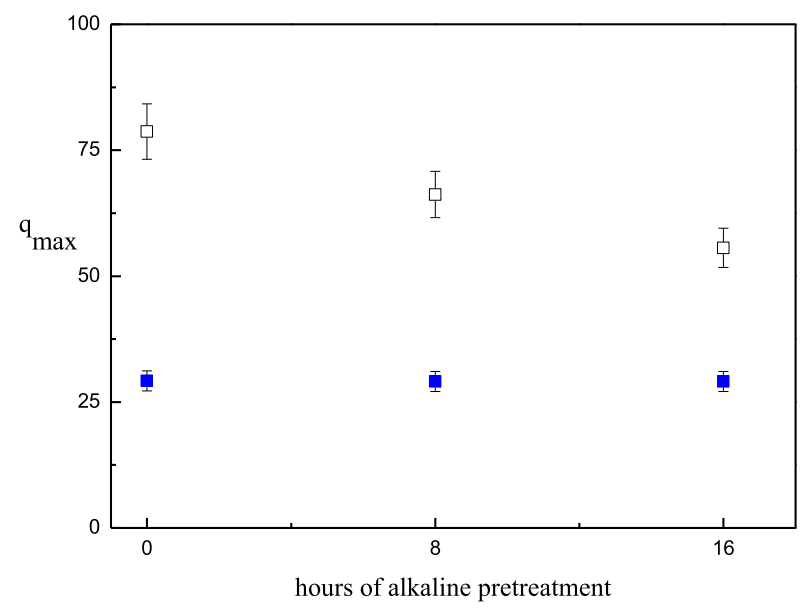

b)

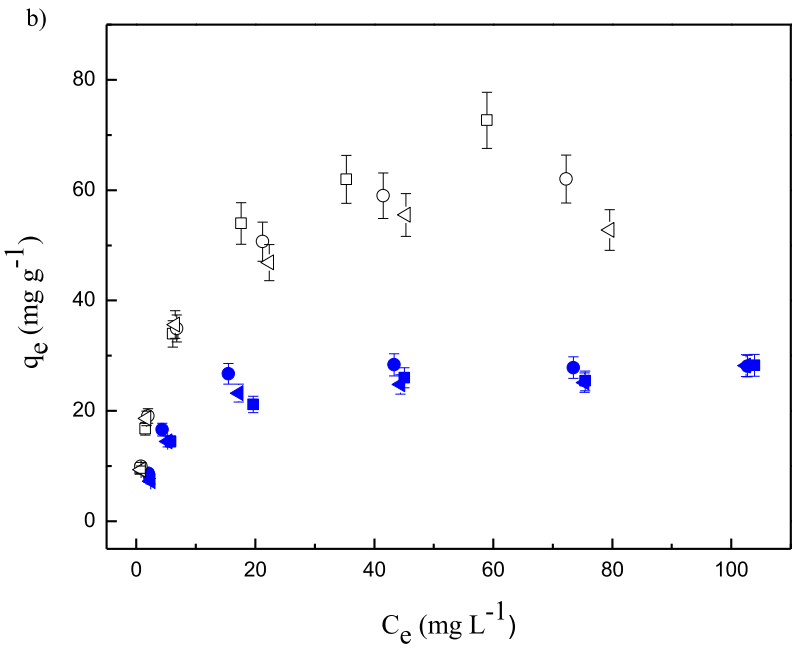

Fig. 6

Fig. 6. Experimental data obtained from batch assays using the fresh and alkaline treated samples at 8 and $16 \mathrm{~h}$ for $\mathrm{Cr}(\mathrm{VI})$ elimination from a water solution at $\mathrm{pH}=2$. A) $\mathrm{q}$ max is the maximum $\mathrm{Cr}(\mathrm{VI})$ elimination capacity per gram of sorbent calculated using the Langmuir model (Eq.1). Full squares correspond to MCM-41- $\mathrm{NH}_{2}-\mathrm{CH}_{3}$ and empty squares for MCM-41-NH . b) Full isotherms obtained from batch assays for mono (empty symbols) and bifunctionalized (full symbols) samples.

41- $\mathrm{NH}_{2}-\mathrm{CH}_{3}$ sample retains its initial $\mathrm{q}_{\max }$ without any change. Table 3 shows $\mathrm{q}_{\max }$ values reported by other authors to remove hexavalent chromium using different types of adsorbents. It can be seen that the values reported in this work for MCM-41- $\mathrm{NH}_{2}$ and $\mathrm{MCM}-41-\mathrm{NH}_{2}-\mathrm{CH}_{3}$ are comparable with those previously reported. For example, the values reported by Cao et al. and Idris et al., $\cong 40 \mathrm{mg}$. $\mathrm{g}^{-1}$ (Table 3 ), using aminopropyl-MCM-41-based adsorbents that did not lead to the reduction of $\mathrm{Cr}$ (VI) to $\mathrm{Cr}$ (III) are very similar to those found for the bifunctionalized samples $[45,46]$. For not silica-based sorbents in acidic working $\mathrm{pH}$ and without $\mathrm{Cr}$ (VI) transformation similar values were reported [47,48]. Parida et al. reported a higher $\mathrm{q}_{\max }$ without $\mathrm{Cr}$ (VI) reduction using an MCM-41-based sorbent modified with $\mathrm{TiO}_{2}$, this was related with the zero point charge of the sorbent surface at the selected $\mathrm{pH}$ value of 5.5 [49]. In the cases were $\mathrm{Cr}(\mathrm{VI})$ reduction was detected the behavior is not linear and a broad $\mathrm{q}_{\max }$ values are reported [14,50,51]. For example it was determined that the silica particle size has an important effect on the sorbent performance; as the sorbent particle size decreases the efficiency in chromium removal increases.

A first important conclusion obtained from these experimental data indicates that the simultaneous presence of aminopropyl and methyl
Table 3

Removal of $\mathrm{Cr}(\mathrm{VI})$ using differents adsorbents as reported in the literature.

\begin{tabular}{|c|c|c|c|c|}
\hline Adsorbent type & $\begin{array}{l}\text { Optimum } \\
\mathrm{pH}\end{array}$ & $\begin{array}{l}\text { Maximum } \\
\text { adsorption } \\
\text { capacity } \\
\left(\mathrm{q}_{\max }\right)(\mathrm{mg} \\
\left.\mathrm{g}^{-1}\right)\end{array}$ & $\begin{array}{l}\text { Reports } \\
\text { reduction } \\
\mathrm{Cr}^{6+} / \mathrm{Cr}^{3+}\end{array}$ & Reference \\
\hline $\begin{array}{l}\text { MCM-41 } \\
\text { functionalized with } \\
\text { APTES }\end{array}$ & 3.5 & 38.6 & No & [45] \\
\hline $\begin{array}{l}\text { MCM-41 } \\
\text { functionalized with } \\
\text { APTES }\end{array}$ & 3.0 & 39.7 & No & [46] \\
\hline $\begin{array}{l}\text { Mesoporous Magnetite } \\
\left(\mathrm{Fe}_{3} \mathrm{O}_{4}\right) \\
\text { Nanospheres }\end{array}$ & 4.0 & 8.9 & No & [47] \\
\hline $\begin{array}{l}\text { Spent tea-supported } \\
\text { magnetite } \\
\text { nanoparticles }\end{array}$ & 2.0 & 30.0 & No & [48] \\
\hline $\begin{array}{l}\text { MCM- } 41 \text { modified } \\
\text { with } \mathrm{TiO}_{2}\end{array}$ & $\sim 5.5$ & 120.6 & No & [49] \\
\hline $\begin{array}{l}\text { MCM-41 } \\
\text { functionalized with } \\
\text { APTES }\end{array}$ & 2.0 & $\begin{array}{l}86.4 \\
63.7\end{array}$ & Yes & {$[50]$} \\
\hline $\begin{array}{l}\text { Silica nanocomposite } \\
\text { modified with } \\
\text { polyethyleneimine } \\
\text { (PEI) }\end{array}$ & 2.0 & 120.7 & Yes & [51] \\
\hline $\begin{array}{l}\text { Mesoporous silica } \\
\text { functionalized with } \\
\text { APTES }\end{array}$ & 3.0 & 279.9 & Yes & [14] \\
\hline $\begin{array}{l}\text { MCM-41 } \\
\text { functionalized with } \\
\text { APTES } \\
\text { MCM-41 } \\
\text { functionalized with } \\
\text { APTES-MTMS }\end{array}$ & 2.0 & $\begin{array}{l}78.7 \\
29.2\end{array}$ & $\begin{array}{l}\text { Yes } \\
\text { No }\end{array}$ & This work \\
\hline
\end{tabular}

groups gives rise to a sorbent with a greater stability than that with aminopropyl groups. The bi-functionalized MCM-41 sorbent can be used in acidic conditions and regenerated in basic media many times, remaining without any change its starting capacity to eliminate hexavalent chromium from water. It is important to keep in mind that in previous assays we estimated that for a chromium-loaded hybrid MCM41 sample, $1 \mathrm{~h}$ in contact with aqueous basic solution $(\mathrm{pH}>8)$ is time enough to desorb all the sorbed metal [18]. Thus, the alkaline pretreatments realized over the samples in this work can be considered that represent 8 and 16 desorption-regeneration cycles in more drastic conditions $(\mathrm{pH}=10)$. In Fig. 6 it can be seen that, after a pretreatment equivalent to 16 regeneration cycles, MCM- $41-\mathrm{NH}_{2}$ has a $\mathrm{q}_{\max }$ about 1.9 times higher than MCM-41- $\mathrm{NH}_{2}-\mathrm{CH}_{3}$. However, is important to remark that, in a rough estimation, could be predict (by a linear fitting of the experimental results) that after about 35 regeneration cycles the adsorption capacity of MCM-41- $\mathrm{NH}_{2}$ would fall below that of MCM-41- $\mathrm{NH}_{2}-\mathrm{CH}_{3}$.

A second point results evident from the comparison of absolute values of $\mathrm{q}_{\max }$ obtained for the mono and bi-functionalized samples. The initial $\mathrm{q}_{\max }$ values were 78.7 and $29.2 \mathrm{mg} \mathrm{g}^{-1}$ for MCM-41- $\mathrm{NH}_{2}$ and MCM-41- $\mathrm{NH}_{2}-\mathrm{CH}_{3}$, respectively. This difference can be understood considering the ability of aminopropyl-functionalized MCM-41 materials to reduce $\mathrm{Cr}(\mathrm{VI})$ to $\mathrm{Cr}(\mathrm{III})$ [50]. When $\mathrm{MCM}-41-\mathrm{NH}_{2}$ was used as sorbent the concentration of the different $\mathrm{Cr}$ species in the supernatant were of $51.3 \mathrm{mg} \mathrm{L}^{-1}$ for $\mathrm{Cr}(\mathrm{VI})$, and $26.3 \mathrm{mg} \mathrm{L}^{-1}$ for $\mathrm{Cr}(\mathrm{III})$, given rise to a total $\mathrm{Cr}(\mathrm{VI})$ elimination capacity of $78.7 \mathrm{mg} \mathrm{g}^{-1}$. These values indicate that $\mathrm{Cr}(\mathrm{VI})$ elimination from water proceed through a mixed adsorption-reduction process. On the contrary, in the supernatant obtained after the adsorption assays with the samples MCM-41- $\mathrm{NH}_{2}-\mathrm{CH}_{3}$, MCM-41- $\mathrm{NH}_{2}-\mathrm{CH}_{3}-8$ and MCM-41- $\mathrm{NH}_{2}-\mathrm{CH}_{3}-16$, only $\mathrm{Cr}(\mathrm{VI})$ was found and not $\mathrm{Cr}$ (III). This indicates that the bi-functionalized samples are not able to reduce $\mathrm{Cr}(\mathrm{VI})$ to $\mathrm{Cr}(\mathrm{III})$. 
As it was mentioned previously, methyl groups have a higher hydrophobic character than aminopropyl groups. This property would explain the higher robustness of the MCM- $41-\mathrm{NH}_{2}-\mathrm{CH}_{3}$ structure, which remains undamaged in hydrolyzing conditions (aqueous medium and alkaline $\mathrm{pH}$ ): non-polar heads of this second functionalizing group would inhibit the approaching of the water molecules to the solid surface, avoiding in this way the hydrolysis of $\mathrm{Si}-\mathrm{O}-\mathrm{Si}$ bonds. Besides, the capacity to carry out a mixed mechanism of adsorption-reduction of hexavalent chromium would be directly related to the existence of free silanols and aminopropyl groups neighboring each other. If instead, as it was previously demonstrated, the surface silanols are blocked with other species such as cations, this capability is suppressed [9]. We propose the following explanation for the mechanism of chromium adsorption-reduction by MCM-41- $\mathrm{NH}_{2}$ sample: in the first step an $\mathbf{a}$

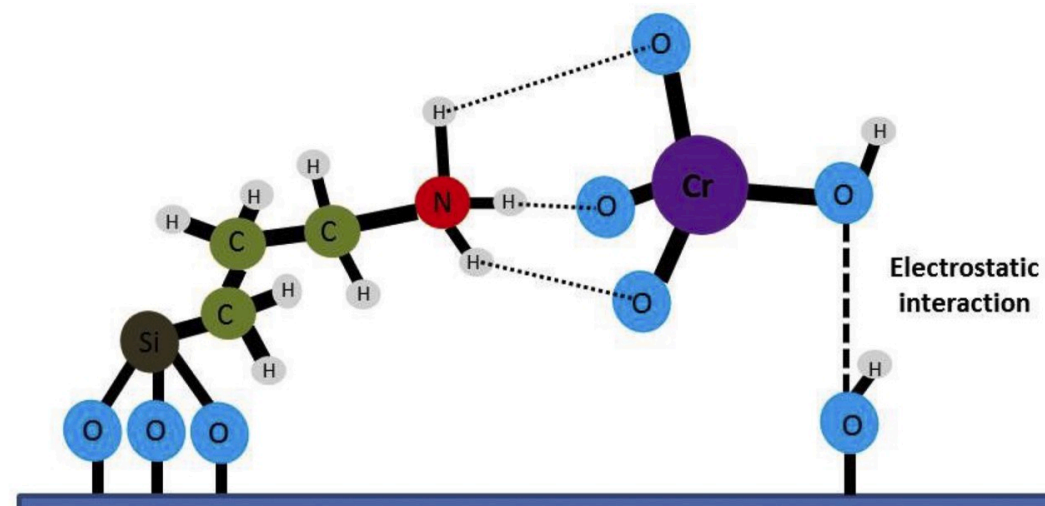

Scheme 2. Representation of the role of each functional group in the occurrence (or not) of the mixed adsorption-reduction mechanism of $\mathrm{Cr}(\mathrm{VI})$ in aminopropyl-MCM-41 based-sorbents. a) Interaction between $\mathrm{HCrO}_{4}^{-}$and $\mathrm{Si}-\mathrm{OH}$ at the $\mathrm{MCM}-41-\mathrm{NH}_{2}$ surface, b) the presence of a cation block the free $\mathrm{Si}-\mathrm{OH}$ avoiding the interaction $\mathrm{HCrO} 4--\mathrm{HO}-\mathrm{Si}$ and therefore the $\mathrm{Cr}(\mathrm{VI})$ reduction does not occurs [9], c) MCM-41- $\mathrm{NH}_{2}-\mathrm{CH}_{3}$ surface representation, here the surface silanols were replaced in a major extent and thus $\mathrm{Cr}(\mathrm{VI})$ reduction is not possible.

b

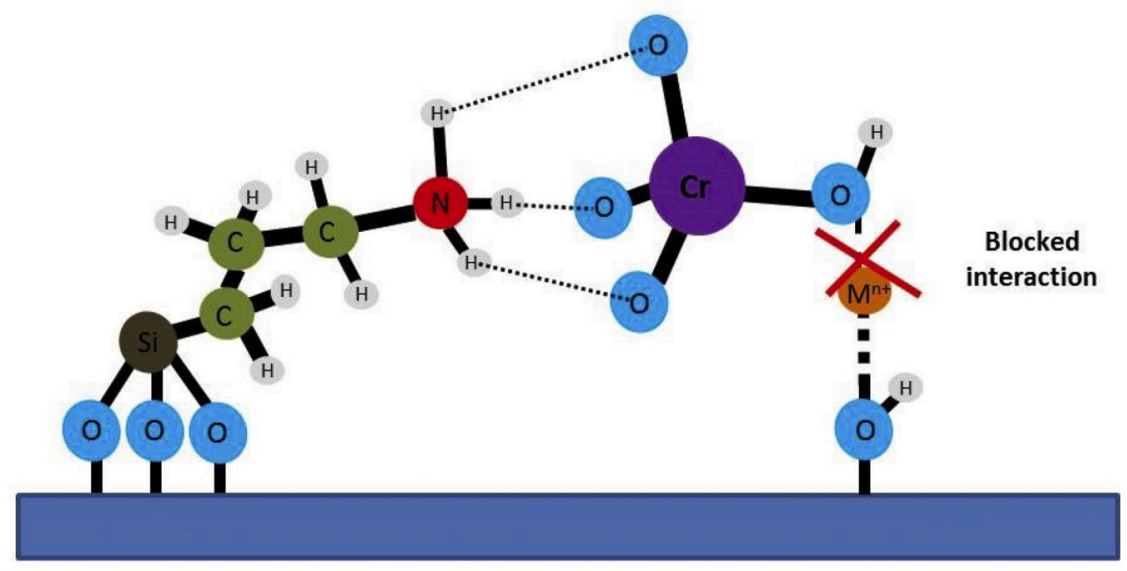

c

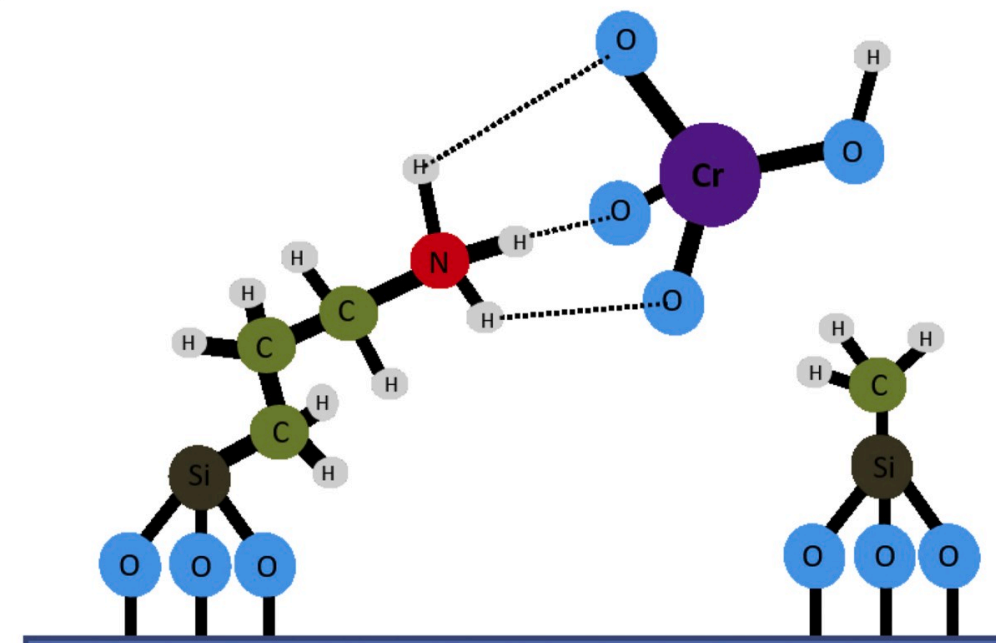


electrostatic interaction between $\mathrm{HCrO}_{4}^{-}$and positively charged ammonium surface species would be produced. When neighbor free silanols are present, an electrostatic attraction between the oxygen atom of $-\mathrm{OH}$ from $\mathrm{HCrO}_{4}^{-}$and silanols would occur [52]. Consequently, the $\mathrm{Cr}-\mathrm{OH}$ bond would be weakened and broken (Scheme 2-a). On the contrary, if neighbor silanol sites are blocked, for example by electrostatic interactions with any metal cations $\left(\mathrm{M}^{\mathrm{n}+}\right)$ present in the water matrix, the interaction between $\mathrm{HCrO}_{4}^{-}-\mathrm{HO}-\mathrm{Si}$ could not occur (Scheme 2-b). On the other hand, in Scheme 2-c, is depicted the surface of the MCM-41- $\mathrm{NH}_{2}-\mathrm{CH}_{3}$ sample. In this new situation, a great number of residual silanols groups have been blocked or transformed with trimethylsilyl groups. Therefore, the interaction that would weaken the bond $\mathrm{Cr}-\mathrm{OH}$ could not be produced and the reduction would not be possible.

Finally, comparing MCM-41- $\mathrm{NH}_{2}$ with the samples obtained after the alkaline treatment, MCM-41- $\mathrm{NH}_{2}-8$ and MCM-41- $\mathrm{NH}_{2}-16$ (empty squares in Fig. 6-a), the decreasing tendency in $q_{\max }$ can be explained taking into account the aminopropyl groups leaching jointly with the mesostructure damage, as it was demonstrated by the textural properties and the TGA measurements (Tables 1 and 2). On the other hand, the starting bi-functionalized sample and those obtained by alkaline treatments, showed no variation in $\mathrm{q}_{\text {max }}$. Again, this last observation agrees with the characterization data analysis that shows greater chemical and structural stability of the bi-functionalized MCM- 41 .

\section{Conclusions}

Two MCM-41-based composites were synthesized and tested as prospect materials for hexavalent chromium elimination from water. Batch adsorption assays were realized at acidic conditions $(\mathrm{pH}=2)$. Besides, and considering that chromium species desorb from solids surface at basic conditions, long time regeneration procedures were simulated by treating the composites in basic aqueous solutions $(\mathrm{pH}=$ 10); after these treatments the resulted samples were tested again toward chromium removal. The first composite has aminopropyl functionalities while the other features aminopropyl and methyl surface groups. According to TGA and FT-IR experiments jointly the textural properties comparison, the presence of the methyl moieties increases the hydrophobicity of the sorbent's surface. This proved to be a key point in improvement of the MCM-41-based composite stability. The higher hydrophobicity explain the higher robustness of the bi-functionalized MCM-41 structure, which remains undamaged after $16 \mathrm{~h}$ in alkaline aqueous solution $(\mathrm{pH}=10)$. Thus, while the aminopropyl-MCM-41 sample suffer a drop of about 30\%, the bi-functionalized MCM-41 sample retains the capacity to eliminate $\operatorname{Cr}(\mathrm{VI})$ without changes.

The non-polar heads of the methyl-functionalizing group would inhibit the approaching of the water molecules, avoiding the hydrolysis of $\mathrm{Si}-\mathrm{O}-\mathrm{Si}$ bonds of the MCM-41 pores walls. Nevertheless, the incorporation of the methyl groups inhibits the capacity of the aminopropylMCM-41 composite to reduce $\mathrm{Cr}(\mathrm{VI})$ to $\mathrm{Cr}(\mathrm{III})$. The experimental data here exposed also shown that the mixed adsorption-reduction mechanism of $\mathrm{Cr}(\mathrm{VI})$ elimination from water only occurs when there are at the same time aminopropyl and silanol surface entities. The bifunctionalized MCM-41 composite only adsorb $\mathrm{Cr}(\mathrm{VI})$ but not reduces it. This capacity disappears when methyl groups replace the starting silanol groups, neighbors to amino-propyl groups.

\section{Declaration of competing interest}

The authors declare that they have no known competing financial interests or personal relationships that could have appeared to influence the work reported in this paper.

\section{CRediT authorship contribution statement}

Pedro Martin: Data curation, Investigation. Matías Rafti: Data curation, Investigation, Validation, Resources, Writing - review \& editing. Sergio Marchetti: Validation, Visualization, Writing - review \& editing. Nicolas Fellenz: Conceptualization, Data curation, Formal analysis, Funding acquisition, Investigation, Methodology, Project administration, Resources, Supervision, Validation, Visualization, Writing - original draft, Writing - review \& editing.

\section{Acknowledgements}

This work was funded by Universidad Nacional de Río Negro (UNRN) (PI-40-C-650). PPM thanks Consejo Nacional de Investigaciones Científicas y Técnicas (CONICET) for his post-graduate student fellowship. MR, SM and NF are CONICET staff researchers.

\section{References}

[1] D.P. Sahoo, D. Rath, B. Nanda, K.M. Parida, Transition metal/metal oxide modified MCM-41 for pollutant degradation and hydrogen energy production: a review, RSC Adv. 5 (2015) 83707-83724.

[2] S. Dehghani, M. Haghighi, Sono-dispersion of MgO over Al-Ce-doped MCM-41 bifunctional nanocatalyst for one-step biodiesel production from acidic oil: influence of ultrasound irradiation and Si/Ce molar ratio, Ultrason. Sonochem. 54 (2019) 142-152.

[3] P.N.E. Diagboya, E.D. Dikio, Silica-based mesoporous materials; emerging designer adsorbents for aqueous pollutants removal and water treatment, Microporous Mesoporous Mater. 266 (2018) 252-267.

[4] K.K. Das, S. Patnaik, B. Nanda, A.C. Pradhan, K. Parida, $\mathrm{ZnFe}_{2} \mathrm{O}_{4}$-Decorated mesoporous $\mathrm{Al}_{2} \mathrm{O}_{3}$ modified MCM-41: a solar-light-active photocatalyst for the effective removal of phenol and Cr (VI) from water, Chem. Select 4 (2019) 1806-1819.

[5] R. Soltani, M. Dinari, G. Mohammadnezhad, Ultrasonic-assisted synthesis of novel nanocomposite of poly(vinyl alcohol) and amino-modified MCM-41: a green adsorbent for Cd(II) removal, Ultrason. Sonochem. 40 (2018) 533-542.

[6] A. Ulu, S.A.A. Noma, S. Koytepe, B. Ates, Chloro-modified magnetic $\mathrm{Fe}_{3} \mathrm{O}_{4} @$ mcm41 core-shell nanoparticles for L-asparaginase immobilization with improved catalytic activity, reusability, and storage stability, Appl. Biochem. Biotechnol. 187 (2019) 938-956.

[7] E. Cansever Mutlu, A. Birinci Yıldırım, M. Yıldırım, A. Ficai, D. Ficai, F.N. Oktar, M. Ţîţu, A. Çetinkaya, A. Demir, Improvement of antibacterial and biocompatibility properties of electrospray biopolymer films by $\mathrm{ZnO}$ and MCM-41, Polym. Bull. (2019), https://doi.org/10.1007/s00289-019-02937-2.

[8] X. Chen, W.K. Ching, K.F. Lam, W. Wei, K.L. Yeung, An investigation of the selective adsorptions of metals on mesoporous $\mathrm{NH}_{2}$-MCM-41, J. Phys. Chem. C 120 (2016), 18365-18365.

[9] P.P. Martin, M.F. Agosto, J.F. Bengoa, N.A. Fellenz, Zinc and Chromium elimination from complex aqueous matrices using a unique aminopropyl-modified MCM-41 sorbent: temperature, kinetics and selectivity studies, J. Env. Chem. Eng. 5 (2017) 1210-1218.

[10] T. Yokoi, Y. Kubota, T. Tatsumi, Amino-functionalized mesoporous silica as base catalyst and adsorbent, Appl. Catal., A 421-422 (2012) 14-37.

[11] E. Da'na, Adsorption of heavy metals on functionalized-mesoporous silica: a review, Microporous Mesoporous Mater. 247 (2017) 145-157.

[12] J.A.S. Costa, R.A. de Jesus, D.O. Santos, J.F. Mano, L.P.C. Romão, C.M. Paranhos, Recent progresses in the adsorption of organic, inorganic, and gas compounds by MCM-41-based mesoporous materials, Microporous Mesoporous Mater. 291 (2020) 109698.

[13] Y. Bao, X. Yan, W. Du, X. Xie, Z. Pan, J. Zhou, L. Li, Application of aminefunctionalized MCM-41 modified ultrafiltration membrane to remove chromium (VI) and copper (II), Chem. Eng. J. 281 (2015) 460-467.

[14] X. Lai, D. Sun, Y. Hou, Y. Zuo, Y. Li, L. Zhang, Amino-functionalized multilayer core-shell mesoporous organosilica nanospheres for $\mathrm{Cr}(\mathrm{VI})$ removal, Adv. Mater. Interfaces 5 (2018) 1800630.

[15] A. Benhamou, J.P. Basly, M. Baudu, Z. Derriche, R. Hamacha, Aminofunctionalized MCM-41 and MCM-48 for the removal of chromate and arsenate, J. Colloid Interface Sci. 404 (2013) 135-139.

[16] R.K. Tandon, P.T. Crisp, J. Ellis, Effect of pH on Chromium(VI) species in solution, Talanta 31 (1984) 227-228.

[17] E. Aranda-García, E. Cristiani-Urbina, Effect of pH on hexavalent and total chromium removal from aqueous solutions by avocado shell using batch and continuous systems, Environ. Sci. Pollut. Res. 26 (4) (2017) 3157-3173.

[18] N. Fellenz, P. Martin, S. Marchetti, F. Bengoa, Aminopropyl-modified mesoporous silica nanospheres for the adsorption of $\mathrm{Cr}(\mathrm{VI})$ from water, J. Por. Mat. 22-3 (2015) 729-738.

[19] F. Raji, M. Pakizeh, Study of $\mathrm{Hg}$ (II) species removal from aqueous solution using hybrid $\mathrm{ZnCl}_{2}-\mathrm{MCM}-41$ adsorbent, Appl. Surf. Sci. 282 (2013) 415-424.

[20] A. Walcarius, L. Mercier, Mesoporous organosilica adsorbents: nanoengineered materials for removal of organic and inorganic pollutants, J. Mater. Chem. 20 (2010) 4478-4511.

[21] S.O. Akpotu, B. Moodley, Synthesis and characterization of citric acid grafted MCM-41 and its adsorption of cationic dyes, J. Environ. Chem. Eng. 4 (2016) 4503-4513. 
[22] K. Braun, A. Pochert, M. Beck, R. Fiedler, J. Gruber, M. Lindén, Dissolution kinetics of mesoporous silica nanoparticles in different simulated body fluids, J. Sol. Gel Sci. Technol. 79 (2) (2016) 319-327.

[23] J.M. Kisler, M.L. Gee, G.W. Stevens, A.J. O'Connor, Comparative studies of silylation methods to improve the stability of silicate MCM-41 in aqueous solutions, Chem. Mater. 15 (2003) 619-624.

[24] S. Oshima, J.M. Perera, K.A. Northcott, H. Kokusen, G.W. Stevens, Y. Komatsu, Adsorption behavior of cadmium(II) and lead(II) on mesoporous silicate MCM-41 separat, Sci. Technol. 41 (2006) 1635-1643.

[25] A. Fellenz, S.G. Marchetti, J.F. Bengoa, R.C. Mercader, S.A.J. Stewart, Synthesis and magnetic characterization of magnetite particles embedded in mesoporous MCM-41, J. Magn. Magn Mater. 306 (2006) 30-34.

[26] R. Ryoo, S. Jun, Improvement of hydrothermal stability of MCM-41 using salt effects during the crystallization process, J. Phys. Chem. B 101 (1997) 317-320.

[27] M. Varache, I. Bezverkhyy, F. Bouyer, R. Chassagnon, F. Baras, F. Bouye, Improving structural stability of water-dispersed MCM-41 silica nanoparticles through post-synthesis pH aging process, J. Nanoparticle Res. 17 (2015) 356.

[28] H.A. Maitlo, K.H. Kim, V. Kumar, S. Kim, J.W. Park, Nanomaterials-based treatment options for chromium in aqueous environments, Environ. Int. 130 (2019) 104748.

[29] B. Saha, C. Orvig, Biosorbents for hexavalent chromium elimination from industrial and municipal effluents, Coord. Chem. Rev. 254 (2010) 2959-2972.

[30] M. Grün, K.K. Unger, A. Matsumoto, K. Tsutsumi, Novel pathways for the preparation of mesoporous MCM-41 materials: control of porosity and morphology, Microporous Mesoporous Mater. 27 (1999) 207-216.

[31] M. Kumar Dinker, P. Shripad Kulkarni, Recent advances in silica-based materials for the removal of hexavalent chromium: a review, J. Chem. Eng. Data 60 (9) (2015) 2521-2540.

[32] S. Dehghani, M. Haghighi, N. Vardast, Structural/texture evolution of CaO/MCM41 nanocatalyst by doping various amounts of cerium for active and stable catalyst: biodiesel production from waste vegetable cooking oil, Int. J. Energy Res. 43 (2019) 1-15.

[33] L. Mercier, T.J. Pinnavaia, Heavy metal ion adsorbents formed by the grafting of a thiol functionality to mesoporous silica molecular sieves: factors affecting $\mathrm{Hg}(\mathrm{II})$ uptake, Environ. Sci. Technol. 32 (1998) 2749-2754.

[34] V. Hernández-Morales, R. Nava, Y.J. Acosta-Silva, S.A. Macías-Sánchez, J.J. Pérez Bueno, B. Pawelec, Adsorption of lead (II) on SBA-15 mesoporous molecular sieve functionalized with -NH2 groups, Microporous Mesoporous Mater. 160 (2012) $133-142$.

[35] B.M. Abu-Zied, M.A. Hussein, A.M. Asiri, Development and characterization of the composites based on mesoporous MCM-41 and polyethylene glycol and their properties, Composites Part B 58 (2014) 185-192.

[36] M. Luechinger, R. Prins, G.D. Pirngruber, Functionalization of silica surfaces with mixtures of 3-aminopropyl and methyl groups, Microporous Mesoporous Mater. 85 (2005) 111-118.

[37] C.H. Lee, T.S. Lin, H.P. Lin, Q. Zhao, S.B. Liu, C.Y. Mou, High loading of C60 in nanochannels of mesoporous MCM-41 materials, Microporous Mesoporous Mater. 57 (2) (2003) 199-209.
[38] B. Arkles, G.L. Larson, A Survey of Properties and Chemistry, third ed., Gelest, Inc., Morrisville, PA, 2013, pp. 177-180.

[39] M. Thommes, K. Kaneko, A.V. Neimark, J.P. Olivier, F. Rodriguez-Reinoso, J. Rouquerol, K.S.W. Sing, Physisorption of gases, with special reference to the evaluation of surface area and pore size distribution (IUPAC Technical Report), Pure Appl. Chem. 87 (9-10) (2015) 1051-1069.

[40] H. Yoshitake, Design of functionalization and structural analysis of organicallymodified siliceous oxides with periodic structures for the development of sorbents for hazardous substances, J. Mater. Chem. 20 (2010) 4537-4550.

[41] N. Velikova, Y. Vueva, Y. Ivanova, I. Salvado, M. Fernandes, P. Vassileva, R. Georgieva, A. Detcheva, Synthesis and characterization of sol-gel mesoporous organosilicas functionalized with amine groups, J. of Non-Crys. Sol. 378 (2013) 89-95.

[42] N.A. Fellenz, J.F. Bengoa, M.V. Cagnoli, S.G. Marchetti, Changes in the surface hydrophobicity degree of a MCM-41 used as iron support: a pathway to improve the activity and the oleins production in the Fischer-Tropsch synthesis, J. Por. Mater. 24 (2017) 1025-1036.

[43] R.R. Sever, R. Alcala, J.A. Dumesic, T.W. Root, Vapor-phase silylation of MCM-41 and Ti-MCM-41, Microporous Mesoporous Mater. 66 (2003) 53-67.

[44] G. Berlier, L. Gastaldi, S. Sapino, I. Miletto, E. Bottinelli, D. Chirio, E. Ugazio, MCM-41 as a useful vector for rutin topical formulations: synthesis, characterization and testing, Int. J. Pharm. 457 (2013) 177-186.

[45] J. Cao, Y. Wu, Y. Jin, P. Yilihan, W. Huang, Response surface methodology approach for optimization of the removal of chromium(VI) by $\mathrm{NH}_{2}-\mathrm{MCM}-41$, J. Taiwan Inst. Chem. Eng. 45 (2014) 860-868.

[46] S.A. Idris, K.M. Alotaibi, T.A. Peshkur, P. Anderson, M. Morris, L.T. Gibson, Adsorption kinetic study: effect of adsorbent pore size distribution on the rate of $\mathrm{Cr}$ (VI) uptake, Microporous Mesoporous Mater. 165 (2013) 99-105.

[47] M. Kumari, C.U. P Jr., D. Mohan, Heavy metals [chromium (VI) and lead (II)] removal from water using mesoporous magnetite $\left(\mathrm{Fe}_{3} \mathrm{O}_{4}\right)$ nanospheres, J. Colloid Interface Sci. 442 (2015) 120-132.

[48] A.A. Babaei, M. Ahmadi, G. Goudarzi, N. Jaafarzadeh, Z. Baboli, Adsorption of chromium(VI) from saline wastewater using spent tea-supported magnetite nanoparticle, Desalinat. Water Treatm. 57 (2016) 12244-12256.

[49] K. Parida, K.G. Mishra, S.K. Dash, Adsorption of toxic metal ion Cr(VI) from aqueous state by $\mathrm{TiO}_{2}$-MCM-41: equilibrium and kinetic studies, J. Hazard Mater. 241- 242 (2012) 395-403.

[50] N. Fellenz, F.J. Perez-Alonso, P.P. Martin, J.L. García-Fierro, J.F. Bengoa, S. G. Marchetti, S. Rojas, Chromium(VI) removal from water by means of adsorptionreduction at the surface of amino-functionalized MCM-41 sorbents, Microporous Mesoporous Mater. 239 (2017) 138-146.

[51] K. Choi, S. Lee, J. Ock Park, J.A. Park, S.H. Cho, S.Y. Lee, J.H. Lee, J.W. Choi, Chromium removal from aqueous solution by a PEI-silica nanocomposite, Sci. Rep. 8 (2018) 1438.

[52] Z. Wu, H. Xiang, T. Kim, M.-S. Chun, K. Lee, Surface properties of submicrometer silica spheres modified with aminopropyltriethoxysilane and phenyltriethoxysilane, J. Colloid Interface Sci. 304 (2006) 119-124. 